\title{
LETTER TO THE JOURNAL
}

Sir,

\section{CONJUNCTIVAL LYMPHOEDMA IN TURNER'S SYNDROME}

A 23 year old female was referred with a swelling of the bulbar conjunctiva of the right eye. This had been present for two years. Topical agents had been ineffective and it had recurred following excision.

On examination, the lower bulbar conjunctiva of the right eye was oedematous with loculation (Fig. 1); the rest of the anterior segment was normal. The intraocular pressure was $17 \mathrm{mmHg}$ and fundoscopy normal. There was no proptosis nor bruit present. The patient exhibited features of Turner's syndrome including shortness of stature, webbing of the neck, cubitus valgus and lymphoedema of both legs. A CAT scan revealed neither orbital nor retro-orbital abnormality.

Biopsies showed abnormal conjunctiva with oedema and fibrosis (Fig. 2) of the stroma with focal overlying epithelial hyperplasia and squamous metaplasia. No dilated lymphatic vessels were seen. There was a mild, focal chronic inflammatory cell infiltrate. Deeper connective tissue showed widely separated, hypocellular collagen bundles (Fig. 3). The findings were interpreted as secondary to chronic oedema.

Previous reports list many ocular features in patients with Turner's syndrome, $, 2,2,3$ some of which may be pathological sequelae and some coincidental. Conjunctival change is limited to one report of telangiectasia. ${ }^{3}$ Lympho-

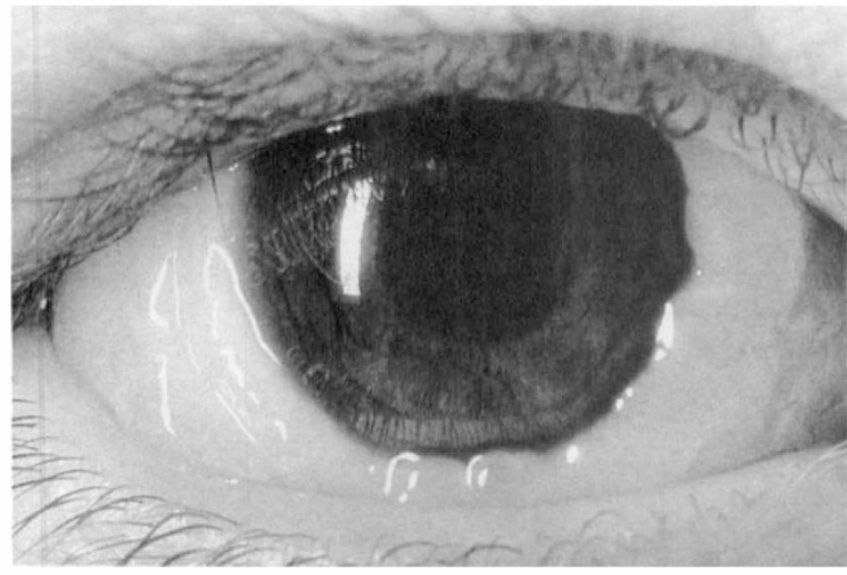

Fig. 1. Right eye showing conjunctival oedema. edema has not been described previously. In this patient, it is noteworthy that the oedema was unilateral, not congenital, persistent and unresponsive to medical or surgical intervention. The histological findings were helpful but inconclusive. Peripheral lymphoedema is a common finding in Turner's syndrome but the underlying pathology is not fully understood.

The reporting of conjunctival lymphoedema with chronic hereditary lymphoedema of the lower extremities (Milroy's disease) ${ }^{4}$ is of interest. It has been suggested that the underlying defect in lymphatic drainage is due to dysplasia or abiotrophy of the lymph vessels possibly related to the age at the onset of the lymphoedema. We postulate that conjunctival lymphoedema in Turner's syndrome is a direct association.

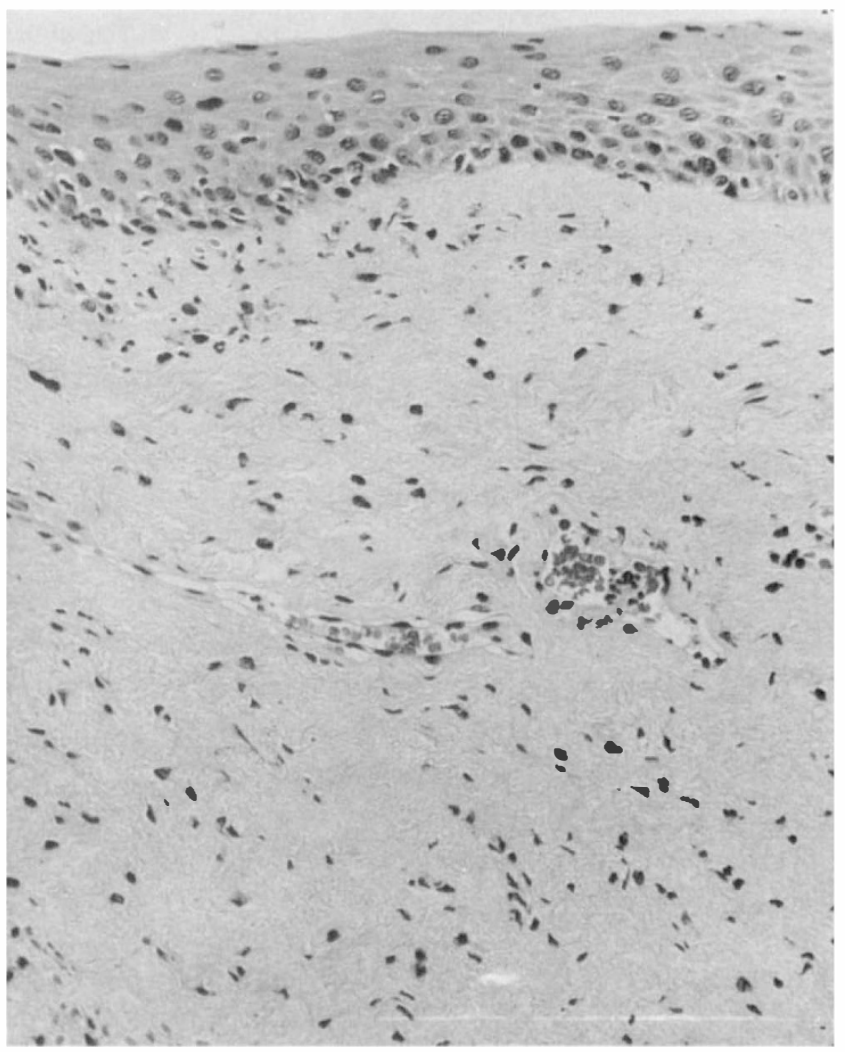

Fig. 2. Conjunctival biopsy showing oedema and fibrosis. 


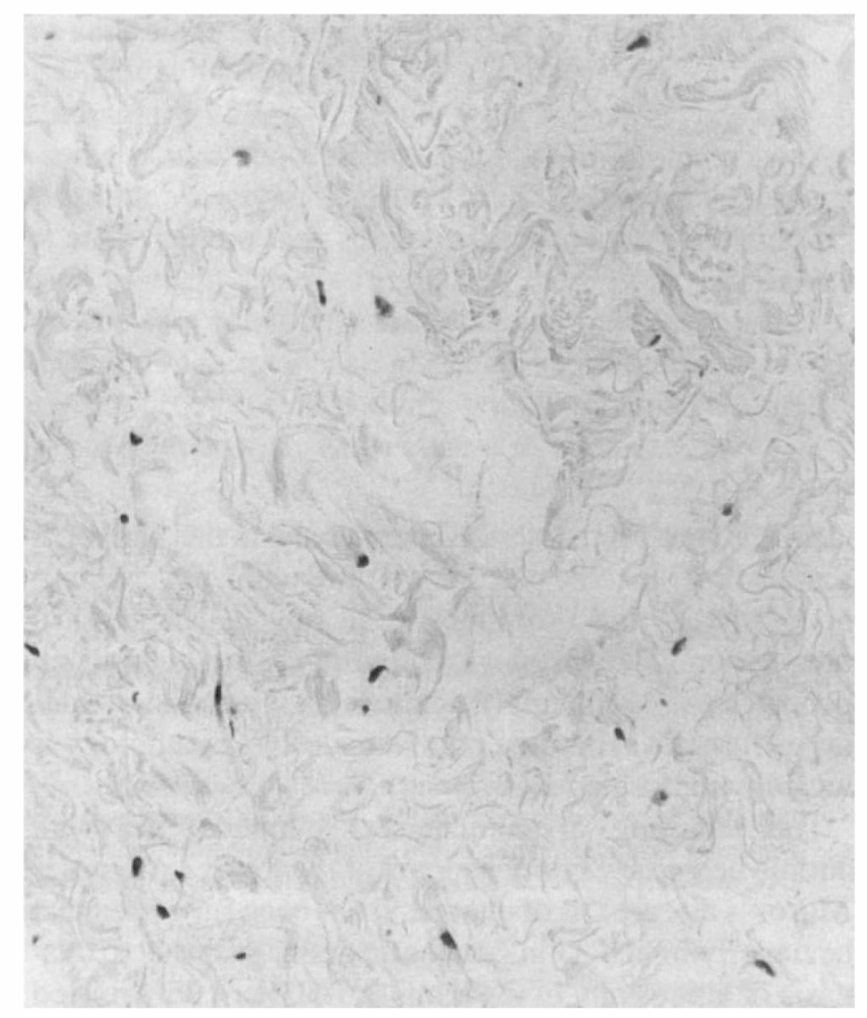

Fig. 3. Conjunctival biopsy showing evidence of chronic oedema.
We are indebted to Mr D Leighton for referring this case and to Dr. G. J. Coast and Dr. P. A. Smith for histology.

Michael W. Austin, FRCS, FCOphth Aberdeen Royal Infirmary

Alan Patterson, MD, FRCS, FCOphth St Paul's Eye Hospital, Liverpool

Richard A. Bates, FRCS, FCOphth

Birmingham and Midland Eye Hospital

\section{REFERENCES}

1. Lessell S and Forbes AP: Eye Signs in Turner's Syndrome, Arch Ophthalmology 1966, 76: 211-13.

2. Mets MB and Maumenee IH: The Eye the Chromosome Surv. Ophthalmology 1983, 28: 20-31.

3. Chrousos GA, Ross JL, Chrousos G, Chu FC, Kenigsberg D, Cutler G, Loriaux OL: Ocular Findings in Turner's Syndrome. Ophthalmology 1984, 91: 926-28.

4. Tabbara KF and Baghdassarian SA: Chronic Hereditary Lymphoedema of the legs with congenital conjunctival lymphoedema. Am J Ophthalmol 1972, 72: 531-2. 